\title{
Aplicação de nitrogênio, potássio e cálcio na cultura da cenoura
}

\section{Luciana Maria da Silva ${ }^{1}$, Scarlet de Aguiar Basílio ${ }^{1}$, Rogério Lamim Silva Junior ${ }^{1}$, Katiane Santiago Silva Benett ${ }^{1}$, Cleiton Gredson Sabin Benett ${ }^{1}$}

${ }^{1}$ Universidade Estadual de Goiás, Campus Ipameri, Ipameri, Goiás, Brasil. E-mail: luy.mari@ hotmail.com,

scarletaguiar@yahoo.com.br, rogeriolamimj@gmail.com, katiane.benett@gmail.com, cleiton.benett@gmail.com

Recebido: 29/12/2016; Aceito: 14/08/2017.

\section{RESUMO}

O presente trabalho teve como objetivo avaliar de forma isolada a aplicação de fontes e doses de nitrogênio, modos de aplicação e doses de potássio e doses e modos de aplicação de nitrocálcio, nas características produtivas da cultura da cenoura. Os experimentos foram realizados em campo na Universidade Estadual de Goiás, Câmpus de Ipameri. O delineamento experimental utilizado em ambos foi o de blocos casualizados em esquema fatorial 2 x 5, com quatro repetições. Os dados foram submetidos à análise de variância (teste F) e as médias comparadas pelo teste de Tukey a $5 \%$ de probabilidade e foram realizadas análise de regressão. As fontes de nitrogênio e épocas não influenciaram nas características produtivas da cultura da cenoura em nenhuma das variáveis analisadas. A utilização de doses de nitrogênio até $103 \mathrm{~kg} \mathrm{ha}^{-1}$ aumenta a produção comercial de cenoura. As doses de potássio influenciaram nas características do comprimento e diâmetro de raiz, classificação comercial, matéria seca da parte aérea e raiz além da produção comercial até a dose de $87,75 \mathrm{~kg} \mathrm{ha}^{-1}$. As doses de nitrocálcio influenciaram positivamente a altura da parte aérea, matéria fresca da parte aérea, produção comercial e produção não comercial da cultura da cenoura até a dose de $311 \mathrm{~kg} \mathrm{ha}^{-1}$ do fertilizante.

Palavras-chave: Daucus carota L., adubação, época de aplicação, produção.

\section{Application of nitrogen, potassium and calcium in carrot culture}

\begin{abstract}
The objective of this study was to evaluate the application of sources and nitrogen doses in an isolated way; Methods of application and doses of potassium and doses and modes of application of nitro calcium in the productive characteristics of the carrot crop. The experiments were carried out in the field at the State University of Goiás, Câmpus de Ipameri. The experimental design used in both was randomized blocks in a $2 \times 5$ factorial scheme, with four replications. The data were submitted to analysis of variance (test $F$ ) and the means were compared by the Tukey test at $5 \%$ probability and regression analysis was performed. Nitrogen sources and seasons did not influence the productive characteristics of the carrot crop in any of the analyzed variables. The use of nitrogen doses up to $103 \mathrm{~kg} \mathrm{ha}^{-1}$ increases the commercial production of carrot. Potassium doses influenced root length, root diameter, commercial classification, shoot dry matter and root yield in addition to commercial production up to $87.75 \mathrm{~kg} \mathrm{ha}^{-1}$. The doses of nitrocalcium positively influenced shoot height, shoot fresh matter, commercial production and non-commercial production of the carrot crop to the $311 \mathrm{~kg} \mathrm{~h}^{-1}$ dose of the fertilizer.
\end{abstract}

Key words: Daucus carota L., fertilization, application season, production. 


\section{Introdução}

A cenoura (Daucus carota L.) tem grande importância social e econômica; raiz de elevado teor de cálcio, vitaminas diversas como B1 e B2 e sais minerais muito importantes na dieta humana. A cenoura pertence ao grupo das raízes tuberosas, sua família é a Apiácea. Planta com raiz aromática e comestível de importância na olericultura pelo grande consumo em todo mundo (NETO et al., 2014).

A cenoura é consumida principalmente na forma "in natura", sendo também utilizada como matéria prima para indústrias processadoras de alimentos (FILGUEIRA, 2012), especialmente na fabricação de conservas conjugadas com outras hortaliças, minimamente processada para alimentos infantis também chamados de "baby foods", alimentos congelados, sucos de cenoura e na atualidade cenoura desidratada (TEIXEIRA et al., 2011).

Atualmente os consumidores tem procurado por cenouras com raízes bem desenvolvidas, lisas, cilíndricas, sem a presença de raízes laterais ou secundarias, uniformes, com comprimento variando entre 20 a $25 \mathrm{~cm}$ e com diâmetro de 3 a $4 \mathrm{~cm}$ (TEIXEIRA et al., 2011).

O cultivo da cenoura pode ser realizado o ano todo, mas é importante conhecer as condições climáticas do local e as cultivares adaptadas às diferentes condições de cultivo. Existem cultivares recomendadas para o plantio no inverno, exigentes em clima ameno, intolerantes à temperatura e pluviosidade elevadas; há também as cultivares recomendadas para o cultivo de verão que apresentam adaptação à temperatura e pluviosidade elevadas (FILGUEIRA, 2012).

A quantidade de fertilizante utilizada principalmente pelos produtores de hortaliças é elevada, sendo que frequentemente não consideram a análise de solo e a exigência da cultura provocando desequilíbrios nutricionais nas plantas, contaminação do solo e da água pela lixiviação e acareamento dos nutrientes para os córregos e mananciais e também redução na produtividade. A realização do parcelamento de fertilizantes é uma prática muito utilizada na produção de hortaliças como alternativa que possibilita maior eficácia do fertilizante na cultura amenizando as perdas por lixiviação e/ou volatilização.

De maneira geral, a adubação nitrogenada $(\mathrm{N})$ e potássica $(\mathrm{K})$ é realizada na maioria das vezes em cobertura e o fornecimento de cálcio $(\mathrm{Ca})$ creditado somente à aplicação de corretivos, calcário e gesso que também são fontes desses nutrientes (RIBEIRO et al, 1999; VAN RAIJ, 1997). Filgueira (2012) relata que pesquisas conduzidas no Brasil mostram que a extração de macronutrientes pela cenoura apresenta a seguinte ordem decrescente: $\mathrm{K}, \mathrm{N}, \mathrm{Ca}, \mathrm{P}, \mathrm{S}$ e $\mathrm{Mg}$, porém os melhores resultados na produtividade da cenoura foram obtidos quando se aplicou o $\mathrm{K}$ em cobertura. Luz et al. (2009) observaram que a aplicação conjunta de fontes de nitrogênio, potássio e cálcio aumentaram a produtividade de raízes de cenoura comerciais e a aplicação isolada somente de $\mathrm{Ca}$ ou de $\mathrm{K}$ proporcionou produção com qualidade inferior.

A adubação em cobertura geralmente deve ser realizada com $40 \mathrm{~kg} \mathrm{ha}^{-1}$ de N. Entretanto, nos plantios em épocas chuvosas, recomenda-se a aplicação de $60 \mathrm{~kg}$ ha $^{-1}$ de $\mathrm{N}$ e $60 \mathrm{~kg} \mathrm{ha}^{-1}$ de $\mathrm{K}_{2} \mathrm{O}$, aos 30 e 60 dias após a emergência (FERREIRA et al., 2016).

$\mathrm{O}$ nitrogênio $(\mathrm{N})$ na planta possui função estrutural, sendo constituinte de aminoácidos, proteínas, bases nitrogenadas, diversas enzimas e materiais de transferência de energia como a clorofila, ADP e ATP; exerce também papel importante nos processos de absorção iônica, fotossíntese, respiração, multiplicação e diferenciação celular (MALAVOLTA et al., 1997).

O potássio (K) na planta tem função nas células, tecidos e na regulação osmótica, no balanço de cátions/ânions, na abertura e fechamento dos estômatos, nas relações hídricas na planta além de estimular o aproveitamento do nitrogênio possibilitando melhor absorção, assimilação, nutrição e consequente produtividade (VIANA; KIEHL, 2010).

$\mathrm{O}$ cálcio $(\mathrm{Ca})$ tem papel importante na estrutura da planta como integrante da parede celular incrementando a resistência mecânica dos tecidos e como neutralizador de ácidos orgânicos no citosol. O cálcio faz parte da pectina por meio dos pectatos de cálcio sendo requerido para a alongação e divisão mitótica celular; isto se reflete no crescimento radicular (PRADO, 2008). Além disso, na membrana celular o Ca é importante por interligar grupos fosfatos/carboxílicos de fosfolipídios e confere estabilidade as proteínas.

Desta forma, tendo em vista o mercado da cultura da cenoura e a adição desta hortaliça na dieta alimentar bem como para outras finalidades, estes estudos se tornam de suma importância para o sucesso do cultivo permitindo que os produtores obtenham maior lucratividade e qualidade de produção. Além disso, existem poucas pesquisas sobre a aplicação de nitrogênio, potássio e cálcio na cultura da cenoura.

Este trabalho teve como objetivo avaliar a aplicação de fontes e doses de nitrogênio; modos de aplicação e doses de potássio, doses e modos de aplicação de nitrogênio e cálcio (nitrocálcio) nas características produtivas da cultura da cenoura.

\section{Material e Métodos}

Foram realizados três experimentos, em campo, no período entre setembro e dezembro de 2014 na fazenda experimental da Universidade Estadual de Goiás (UEG), Câmpus Ipameri, localizada no município de 
Ipameri-GO com $17^{\circ} 43^{\prime}$ de latitude sul e $48^{\circ} 22^{\prime}$ de longitude oeste e altitude de $800 \mathrm{~m}$.

O clima da região, segundo a classificação de Köppen é definindo como Tropical Úmido (Aw), constando temperaturas elevadas com chuvas no verão e seca no inverno. O solo da área experimental é classificado como Latossolo Vermelho-Amarelo Distrófico (SANTOS et al., 2013).

Os atributos químicos e físicos do solo foram determinados antes da instalação do experimento, segundo metodologia proposta por Ribeiro et al. (1999) com os seguintes atributos químicos nas camadas 0,00,20 m: $19 \mathrm{mg} \mathrm{dm}^{-3}$ de P (Melich); $30 \mathrm{~g} \mathrm{dm}^{-3}$ de M.O.; 5,3 de $\mathrm{pH}\left(\mathrm{CaCl}_{2}\right) ; \mathrm{K}, \mathrm{Ca}, \mathrm{Mg}$ e $\mathrm{H}+\mathrm{Al}=3,9 ; 35,0 ; 11,0$ e $28,0 \mathrm{mmol}_{\mathrm{c}} \mathrm{dm}^{-3}$, respectivamente e $64 \%$ de saturação por bases, os atributos físicos foram: argila: $390 \mathrm{~g}$, silte: $97 \mathrm{~g}$ e areia: $513 \mathrm{~g}$.

No primeiro experimento foram avaliados isoladamente, a aplicação de fontes e doses de nitrogênio na cultura da cenoura. No segundo experimento utilizou-se isoladamente, modos de aplicação e doses de potássio e no terceiro experimento foram avaliados doses e modos de aplicação de nitrogênio e cálcio (nitrocálcio) na cultura da cenoura.

$\mathrm{O}$ delineamento experimental utilizado em cada um dos três experimentos foi o de blocos casualizados, arranjados em esquema fatorial $2 \times 5$, com quatro repetições.

Para o experimento com nitrogênio, foram usadas as doses de 0, 40, 80, 120 e $160 \mathrm{~kg} \mathrm{ha}^{-1}$, em cobertura e, como fonte, uréia comum e uréia revestida por polímero, parcelando as aplicações aos 15 e 30 dias após a emergência.

No experimento com potássio foram avaliadas a aplicação no plantio e em cobertura, utilizando-se as doses de 0, 30, 60, 90 e $120 \mathrm{~kg} \mathrm{ha}^{-1}$, as aplicações foram realizadas no plantio e a aplicação em cobertura foi realizada 25 dias após a emergência utilizando cloreto de potássio como fonte.

Para o experimento com aplicação conjunta de nitrogênio e cálcio (nitrocálcio) foram avaliadas a aplicação no plantio e em cobertura, utilizando-se as doses de 0,150,300, 450 e $600 \mathrm{~kg} \mathrm{ha}^{-1}$, sendo aplicado no plantio e em cobertura aos 20 dias após a emergência utilizando como fonte o nitrato de cálcio constituído de $14 \%$ de $\mathrm{N}$ e $18 \%$ de Ca. Cada experimento foi analisado independentemente.

As parcelas tiveram dimensões de 1,0 x 1,0 m, sendo constituídas por cinco linhas dispostas de $0,2 \mathrm{~m}$ entre linhas e 0,05 entre plantas, sendo considerada como área útil as três linhas centrais. A adubação básica foi realizada conforme análise do solo antes da instalação.

O controle de plantas invasoras foi realizado através de capinas manual, e os demais tratos culturais e fitossanitários conforme recomendados para a cultura. $\mathrm{O}$ fornecimento de água foi efetuado por meio de sistema de irrigação por aspersão convencional.

Foram realizadas as seguintes avaliações: comprimento de raízes em 10 plantas da área útil de cada parcela, utilizando uma fita métrica; altura da planta medindo-se a distância entre o ápice da folha e a base do colo da raiz em 10 plantas na área útil da parcela utilizando uma régua graduada; diâmetro de raízes obtido através da média entre a parte superior e inferior da raiz com o auxílio de um paquímetro digital; matéria fresca da parte aérea realizando a pesagem de 10 plantas da área útil de cada parcela; matéria seca da parte aérea e raiz obtido de 10 plantas da área útil de cada parcela, secas em estufa de circulação de ar forçada com temperatura de $65^{\circ} \mathrm{C}$ até obterem peso constante; classificação comercial obtida com a colheita de toda área útil da parcela e identificada, sendo posteriormente realizada a classificação quanto ao comprimento conforme escala adaptada de CEAGESP (2000):1 $(\geq 1 \mathrm{a}<10 \mathrm{~cm}) ; 2(\geq 10 \mathrm{a}<14 \mathrm{~cm}) ; 3(\geq 14 \mathrm{a}<18$ $\mathrm{cm}) ; \quad 4(\geq 18$ a $<22 \mathrm{~cm})$ e $5(\geq 22$ a $<26 \mathrm{~cm})$; produtividade comercial obtida com a pesagem das raízes sem defeito presentes na área útil de cada parcela e posteriormente pesadas; produtividade não comercial obtida com a identificação das raízes com defeito (raízes bifurcadas, deformadas e com ramificações excessivas, com presença de galhas) presente na área útil de cada parcela e posteriormente pesadas; produtividade total, ou seja a soma da produtividade comercial e não comercial.

Os dados foram submetidos à análise de variância (teste F) e as médias comparadas pelo teste de Tukey a $5 \%$ de probabilidade, quando significativo para as doses foram realizadas análise de regressão. As análises estatísticas foram processadas utilizando-se o programa de análise estatística Sanest (ZONTA et al., 1987).

\section{Resultados e Discussão}

\section{Primeiro experimento (aplicação de nitrogênio)}

Ao se avaliar interação entre fontes e doses de nitrogênio e somente fontes de nitrogênio pode-se observar nenhum efeito significativo para qualquer das variáveis analisadas (Tabela 1). Mesmo não havendo diferença significativa entre as fontes de nitrogênio, a fonte ureia revestida resultou em valores maiores nas variáveis em comparação com a ureia normal; tal fato pode ser explicado devido à liberação lenta da ureia revestida.

Para a produção comercial mesmo não havendo efeito significativo para as fontes utilizadas podemos observar um aumento de $12 \%$ quando se utilizou a fonte ureia revestida (Tabela 1 ). 
Tabela 1. Valores médios para comprimento de raiz (COMPR), altura da parte aérea (APA), diâmetro de raiz (DIAR), classificação comercial (CLASS), matéria fresca da parte aérea (MFPA), matéria seca da parte aérea (MSPA), matéria fresca de raiz (MFR), matéria seca de raiz (MSR) e produção comercial (PCO) em função das fontes de nitrogênio na cultura da cenoura. Ipameri-GO, 2015.

\begin{tabular}{|c|c|c|c|c|c|}
\hline \multirow{2}{*}{ Fontes } & COMPR & APA & & & \multirow{2}{*}{ CLASS } \\
\hline & \multicolumn{4}{|c|}{ 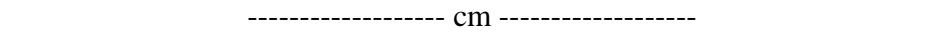 } & \\
\hline Ureia Normal & $14,31 \mathrm{a}$ & $55,11 \mathrm{a}$ & \multicolumn{2}{|c|}{$2,45 \mathrm{a}$} & $2,45 \mathrm{a}$ \\
\hline Ureia Revestida & $15,41 \mathrm{a}$ & 55,78 a & \multicolumn{2}{|c|}{$2,58 \mathrm{a}$} & $2,65 \mathrm{a}$ \\
\hline Valor de F & $4,074 \mathrm{~ns}$ & $0,228 \mathrm{~ns}$ & \multicolumn{2}{|c|}{$1,043 \mathrm{~ns}$} & $1,565 \mathrm{~ns}$ \\
\hline $\mathrm{CV}(\%)$ & 11,64 & 7,99 & \multicolumn{2}{|c|}{16,37} & 12,82 \\
\hline \multirow{2}{*}{ Fontes } & MFPA & MSPA & MFR & MSR & $\mathrm{PCO}$ \\
\hline & \multicolumn{4}{|c|}{ 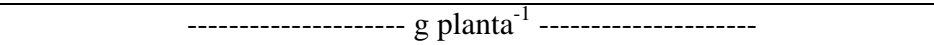 } & $\mathrm{kg} \mathrm{ha}^{-1}$ \\
\hline Ureia Normal & $106,19 \mathrm{a}$ & $21,22 \mathrm{a}$ & $159,38 \mathrm{a}$ & $18,33 \mathrm{a}$ & $9408,25 \mathrm{a}$ \\
\hline Ureia Revestida & 106,59 a & $20,92 \mathrm{a}$ & $176,71 \mathrm{a}$ & $18,05 \mathrm{a}$ & $10559,02 \mathrm{a}$ \\
\hline Valor de F & $0,007 \mathrm{~ns}$ & $0,076 \mathrm{~ns}$ & $3,806 \mathrm{~ns}$ & $0,089 \mathrm{~ns}$ & $1,709 \mathrm{~ns}$ \\
\hline CV (\%) & 13,96 & 16,33 & 16,71 & 16,29 & 12,68 \\
\hline
\end{tabular}

${ }_{\mathrm{ns}}$ não significativo a 5 e $1 \%$ de probabilidade, pelo teste F; médias seguidas pela mesma letra, na coluna, não diferem entre si, pelo teste de Tukey, a $5 \%$ de probabilidade.
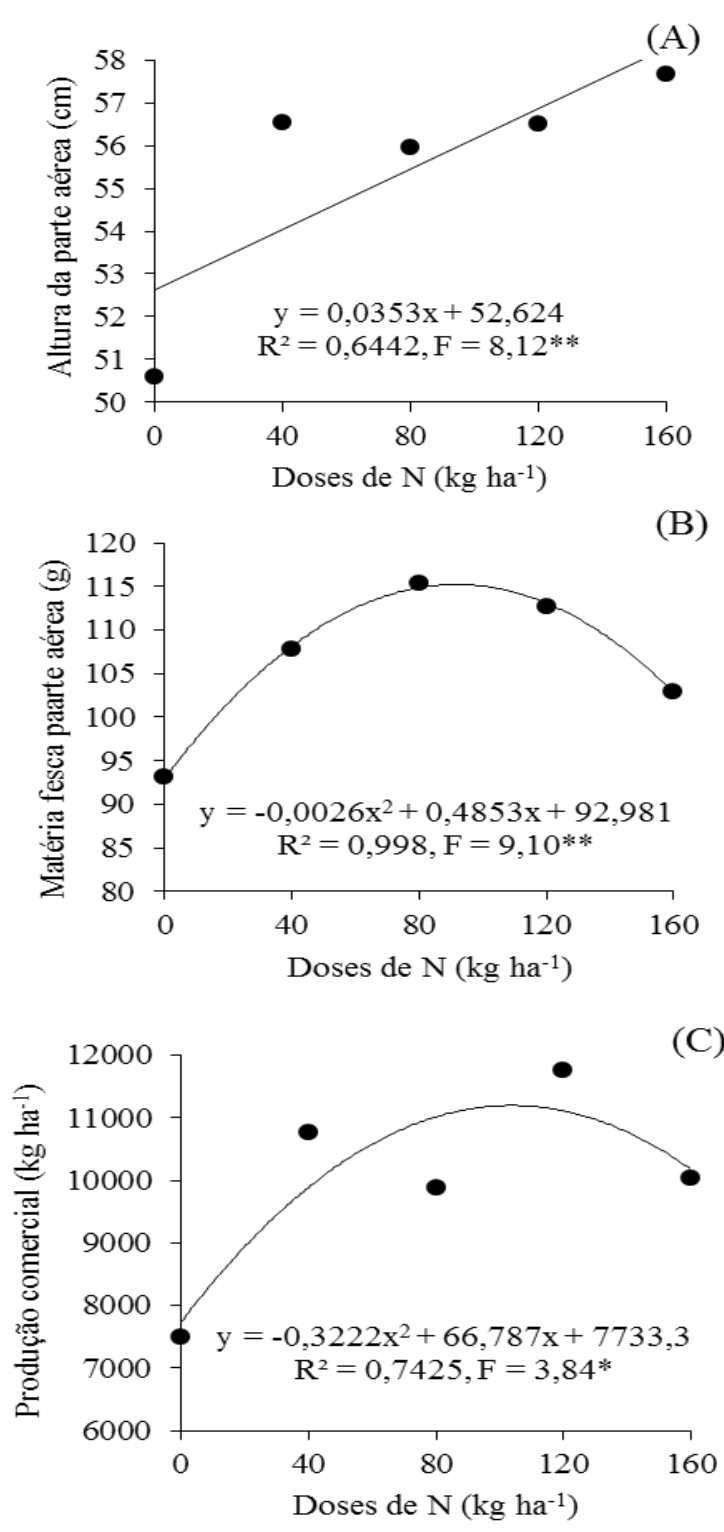

Figura 1. Valores da altura da parte aérea (A), matéria fresca da parte aérea (B) e produção comercial (C) em função das doses de nitrogênio na cultura da cenoura. Ipameri-GO, 2015. *, ** significativo a 5 e $1 \%$ de probabilidade, respectivamente.
Nas doses de nitrogênio ocorreu efeito significativo para a altura da parte aérea, matéria fresca da parte aérea e produção comercial (Figura 1). A altura da parte aérea foi influenciada com $\mathrm{o}$ aumento das doses ajustando-se a regressão linear positiva (Figura 1A).

Os valores da matéria fresca da parte aérea (Figura 1B) e produção comercial (Figura 1C) se ajustaram à regressão quadrática com ponto de máximo de $93,3 \mathrm{e}$ $103,6 \mathrm{~kg} \mathrm{ha}^{-1} \mathrm{de} \mathrm{N}$, respectivamente. Luz et al. (2009) trabalhando com adubação em cobertura de nitrogênio, potássio e cálcio na cultura da cenoura obtiveram produtividade máxima com aplicação de $229,1 \mathrm{~kg} \mathrm{ha}^{-1}$ do formulado 20-00-20, porém estes autores não isolaram os efeitos do $\mathrm{N}$ e do $\mathrm{K}$.

\section{Segundo experimento (aplicação de potássio)}

Constatou-se que não houve efeito significativo para interação entre modos de aplicação e fontes de potássio e somente modos de aplicação de potássio na cultura da cenoura; as características avaliadas não apresentaram diferenças significativas entre si (Tabela 2). Segundo Filgueira (2012), o potássio em cobertura tem apresentado poucos resultados satisfatórios em algumas olerícolas; existe a necessidade de mais pesquisas envolvendo este tipo de aplicação.

Bruno et al. (2007) trabalhando com produtividade e qualidade de sementes e raízes de cenoura cultivada com adubação orgânica e mineral observaram através da adubação com composto orgânico e biofertilizante, via planta, a maior produtividade comercial e o maior comprimento de raízes em média $13,5 \mathrm{~cm}$, conferindo à classificação do tipo média.

Ao avaliar as doses de potássio, pode-se observar efeito significativo para comprimento de raiz, diâmetro de raiz, classificação comercial, matéria seca da parte aérea e da raiz e produção comercial (Figura 2). 
Tabela 2. Valores médios para comprimento de raiz (COMPR), altura da parte aérea (APA), diâmetro de raiz (DIAR), classificação comercial (CLASS), matéria fresca da parte aérea (MFPA), matéria seca da parte aérea (MSPA), matéria fresca de raiz (MFR), matéria seca de raiz (MSR), produção comercial (PCO), produção não comercial (PNC) e produção total (PTOTAL) em função das épocas de aplicação de potássio na cultura da cenoura. Ipameri-GO, 2015.

\begin{tabular}{|c|c|c|c|c|}
\hline \multirow{2}{*}{ Aplicações } & COMPR & APA & DIAR & \multirow{2}{*}{ CLASS } \\
\hline & \multicolumn{3}{|c|}{------------------------- cm ------------------------- } & \\
\hline Plantio & $13,52 \mathrm{a}$ & $42,12 \mathrm{a}$ & $2,38 \mathrm{a}$ & $2,61 \mathrm{a}$ \\
\hline Cobertura & $13,10 \mathrm{a}$ & $43,28 \mathrm{a}$ & $2,32 \mathrm{a}$ & $2,47 \mathrm{a}$ \\
\hline Valor de $\mathrm{F}$ & $0,565 \mathrm{~ns}$ & $0,581 \mathrm{~ns}$ & $0,396 n s$ & $1,094 \mathrm{~ns}$ \\
\hline $\mathrm{CV}(\%)$ & 12,94 & 11,26 & 12,46 & 16,05 \\
\hline \multirow{2}{*}{ Aplicações } & MFPA & MSPA & MFR & MSR \\
\hline & \multicolumn{4}{|c|}{ 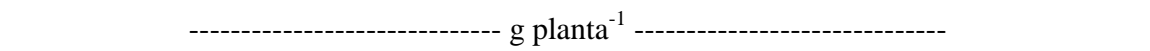 } \\
\hline Plantio & $70,36 \mathrm{a}$ & $9,25 \mathrm{a}$ & $50,02 \mathrm{a}$ & $23,95 \mathrm{a}$ \\
\hline Cobertura & $74,08 \mathrm{a}$ & $10,01 \mathrm{a}$ & $43,10 \mathrm{a}$ & $25,70 \mathrm{a}$ \\
\hline Valor de $\mathrm{F}$ & $1,232 \mathrm{~ns}$ & $3,104 \mathrm{~ns}$ & $0,553 \mathrm{~ns}$ & $1,755 \mathrm{~ns}$ \\
\hline $\mathrm{CV}(\%)$ & 14,63 & 14,15 & 33,12 & 16,82 \\
\hline \multirow{2}{*}{ Aplicações } & \multirow[t]{2}{*}{ PCO } & \multirow{2}{*}{\multicolumn{2}{|c|}{$\begin{array}{c}\mathrm{PNC} \\
\mathrm{kg} \mathrm{ha}{ }^{-1}\end{array}$}} & \multirow[t]{2}{*}{ PTOTAL } \\
\hline & & & & \\
\hline Plantio & & $5755,40 \mathrm{a}$ & $20860,90 \mathrm{a}$ \\
\hline Cobertura & $15190,85 \mathrm{a}$ & \multicolumn{2}{|c|}{$6301,65 \mathrm{a}$} & $21492,50 \mathrm{a}$ \\
\hline Valor de $\mathrm{F}$ & $0,008 \mathrm{~ns}$ & \multicolumn{2}{|c|}{$1,245 \mathrm{~ns}$} & $0,908 \mathrm{~ns}$ \\
\hline $\mathrm{CV}(\%)$ & 26,84 & \multicolumn{2}{|c|}{25,67} & 18,38 \\
\hline
\end{tabular}

ns não significativo a 5 e $1 \%$ de probabilidade, respectivamente, pelo teste $\mathrm{F}$; médias seguidas pela mesma letra, na coluna, não diferem entre si, pelo teste de Tukey, a 5\% de probabilidade.
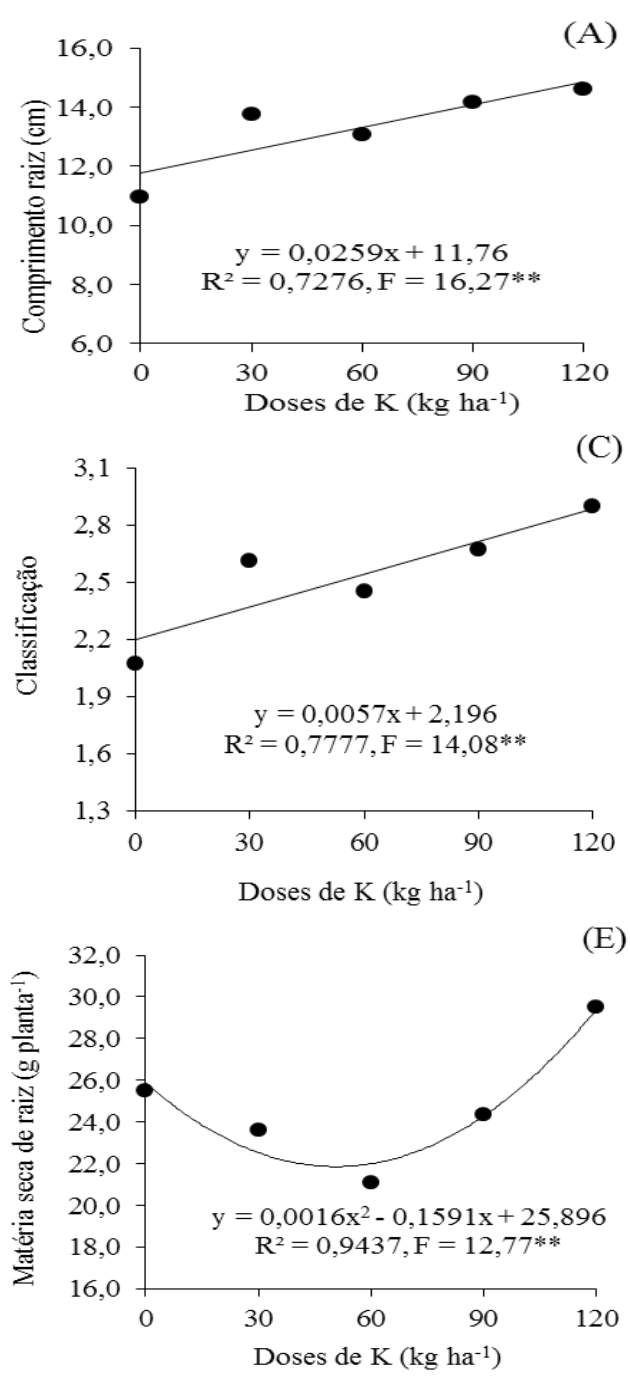

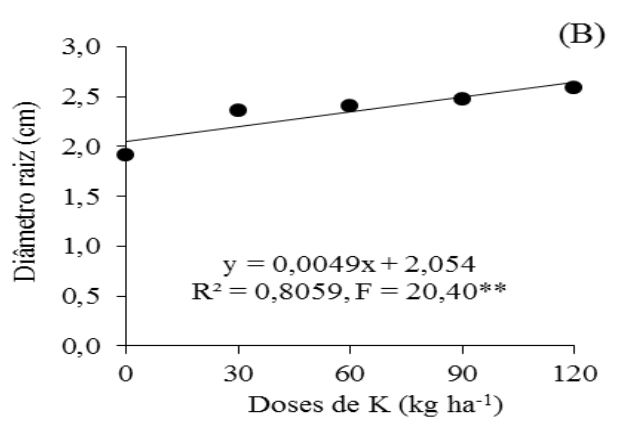

(D)

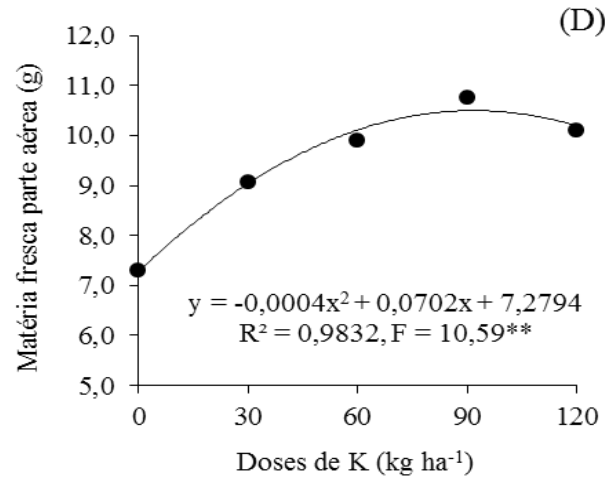

(F)

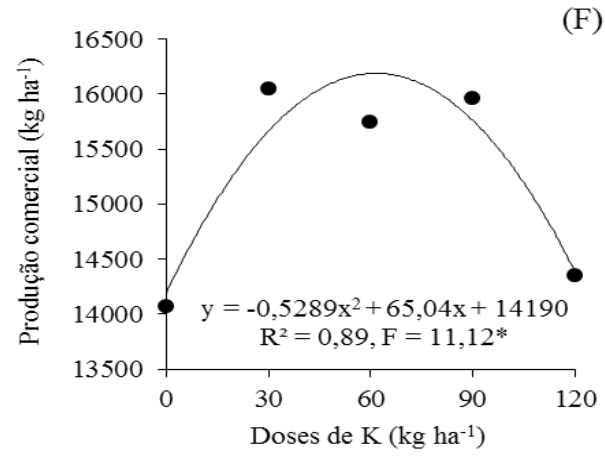

Figura 2. Valores médios do comprimento de raiz (A), diâmetro de raiz (B), classificação comercial (C), matéria seca da parte aérea (D) e matéria seca de raiz (E) e produção comercial (F) em função das doses de potássio na cultura da cenoura. Ipameri-GO, 2015. *, ** significativo a 5 e $1 \%$ de probabilidade, respectivamente. 
Os dados para comprimento, diâmetro de raiz e classificação comercial se ajustaram a regressões lineares positivas (Figuras 2A, 2B e 2C). Zanfirov et al. (2012) avaliando comprimento e diâmetro de raízes, em função da aplicação de potássio em cobertura na cultura da cenoura, não observaram efeito significativo para comprimento de raízes, porém, para diâmetro de raízes (superior e inferior) observaram ajustes dos dados a uma regressão quadrática cujos máximos diâmetros superiores $(38 \mathrm{~mm})$ e inferior $(25 \mathrm{~mm})$ foram estimados para as doses de 47,1 e 45,0 $\mathrm{kg} \mathrm{ha}^{-1}$ de $\mathrm{K}_{2} \mathrm{O}$, respectivamente.

Ao se avaliar matéria seca da parte aérea e matéria seca da raiz em função das diferentes doses de potássio (Figura 2D e 2E) pode se observar que os dados se ajustaram a uma regressão quadrática com ponto de máxima de $87,75 \mathrm{~kg} \mathrm{ha}^{-1}$ de potássio e ponto de mínima de 49,72 $\mathrm{kg} \mathrm{ha}^{-1}$ de potássio, respectivamente.

Quando se avaliou produção comercial por hectare em função das diferentes doses de potássio (Figura 2F) pode-se observar ajuste dos dados uma regressão quadrática com ponto de máxima de $61,49 \mathrm{~kg} \mathrm{ha}^{-1}$ de potássio. Luz et al. (2009) trabalhando com adubação de cobertura com nitrogênio, fósforo e potássio concluíram que a produtividade máxima de cenoura seria obtida com a aplicação de $229 \mathrm{~kg} \mathrm{ha}^{-1}$ do formulado 20-00-20, ou seja, $\mathrm{N}+\mathrm{K}_{2} \mathrm{O}$, porém estes autores não isolaram os efeitos do $\mathrm{N}$ e do $\mathrm{K}$.

Zanfirov et al. (2012) ao comparar sua máxima produtividade obtida $\left(103,8 \mathrm{t} \mathrm{ha}^{-1}\right)$ utilizando $41,6 \mathrm{~kg} \mathrm{ha}^{-}$ ${ }^{1}$ de $\mathrm{K}_{2} \mathrm{O}$ e a testemunha sem aplicação de potássio $(90,7$ $\mathrm{t} \mathrm{ha}^{-1}$ ) obteve uma diferença de $14 \%$, ocorrendo assim aumento na produtividade.

Terceiro experimento (aplicação de nitrogênio e cálcio)

Constatou-se que não houve efeito significativo para interação entre modos de aplicação e doses de nitrocálcio; as características avaliadas não apresentaram diferenças significativas entre si. Na Tabela 3 são apresentados os dados referentes ao crescimento, desenvolvimento e produção das plantas de cenoura em função das épocas de aplicação de nitrocálcio.

Quando se avaliou a influência da época de aplicação de nitrocálcio sobre as variáveis massa fresca e seca da parte aérea e raiz observou-se efeito significativo somente para as variáveis relacionadas à parte aérea apontando maior eficácia para aplicação do nitrocálcio no plantio da cenoura. (Tabela 3 ).

A época de aplicação de nitrocálcio na cultura da cenoura não influenciou significativamente nas variáveis comprimento de raiz, altura da parte aérea, diâmetro de raiz, classificação comercial, matéria fresca e seca de raiz, produção comercial, produção não comercial e produção total (Tabela 3). Estes resultados são semelhantes aos encontrados por Luz et al. (2009) que afirmam não haver alteração as características produtivas da cenoura com aplicação de nitrocálcio em cobertura isoladamente como é o caso da produção total de raízes onde os autores também não observaram diferença significativa.

Tabela 3. Valores médios para o teor de nitrogênio foliar (TNF), comprimento de raiz (COMPR), altura da parte aérea (APA), diâmetro de raiz (DIAR), classificação comercial (CLASS), matéria fresca da parte aérea (MFPA), matéria seca da parte aérea (MSPA), matéria fresca de raiz (MFR), matéria seca de raiz (MSR), produção comercial (PCO), produção não comercial (PNC) e produção total (PTOTAL) em função das épocas de aplicação de nitrocálcio na cultura da cenoura. Ipameri-GO, 2015.

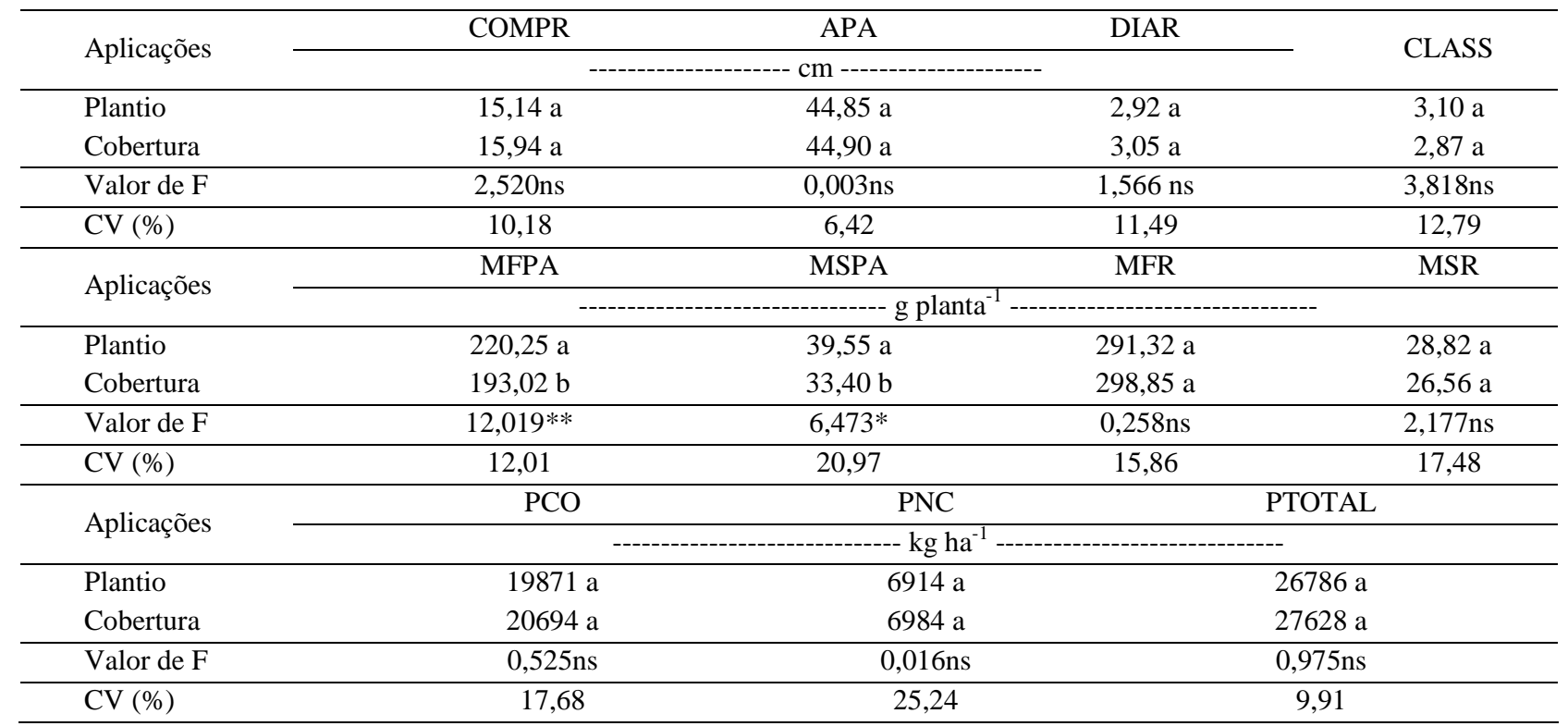

ns, *, ** - não significativo e significativo a 5 e $1 \%$ de probabilidade, pelo teste F; médias seguidas pela mesma letra, na coluna, não diferem entre si, pelo teste de Tukey, a $5 \%$ de probabilidade. 
Para as doses de nitrocálcio houve influência significativa para as variáveis altura da parte aérea, matéria fresca da parte aérea, produção comercial e produção não comercial (Figura 3).

Os valores de altura da parte aérea foram influenciados pela aplicação do nitrocálcio e se ajustaram à regressão linear positiva (Figura 3A). Observando o comportamento das plantas através da variável matéria fresca da parte aérea é possível notar o efeito significativo do aumento das doses de nitrocálcio cujos valores se ajustaram à uma regressão linear positiva (Figura 3B). Os resultados observados por

(A)

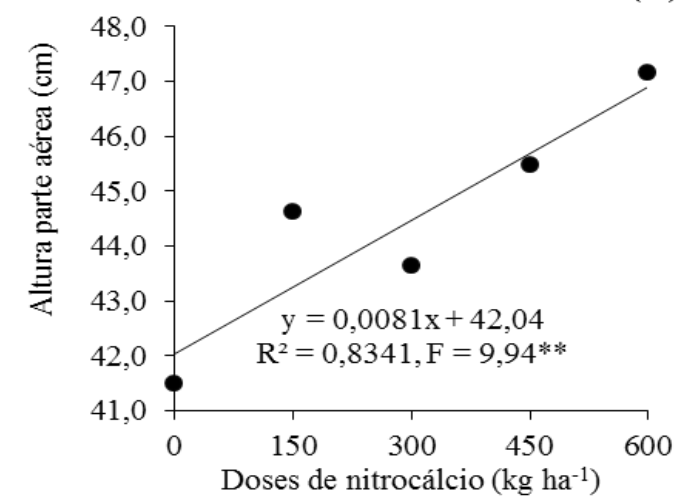

(C)

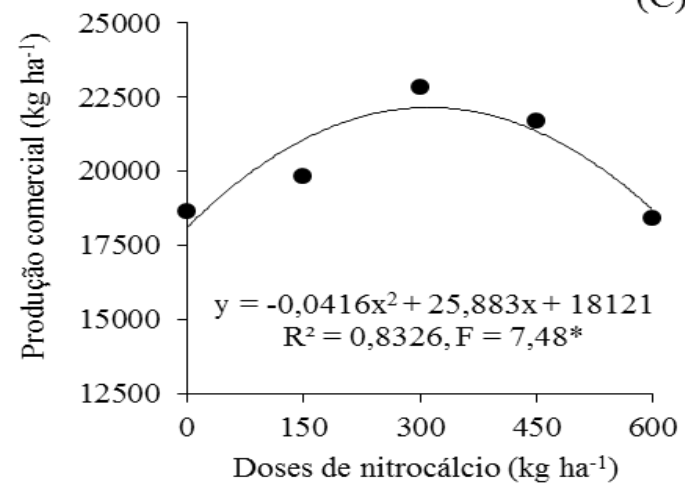

Costa et al. (2012) apresentaram diferença significativa de acordo com o aumento das doses.

Para o aumento das doses de nitrocálcio a variável produção comercial apresentou diferença significativa na produção de acordo com as doses se ajustando à regressão quadrática com valores máximos estimados em $311 \mathrm{~kg} \mathrm{ha}^{-1}$ de nitrocálcio (Figura 3C).

Ao observar a variável produção não comercial houve diferença significativa entre as doses se ajustando à regressão quadrática com valores mínimos estimados em 259,8 $\mathrm{kg} \mathrm{ha}^{-1}$ de nitrocálcio (Figura 3D).

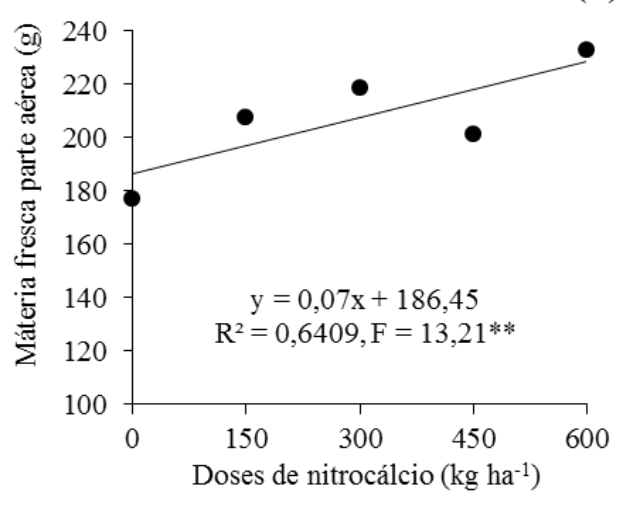

(D)

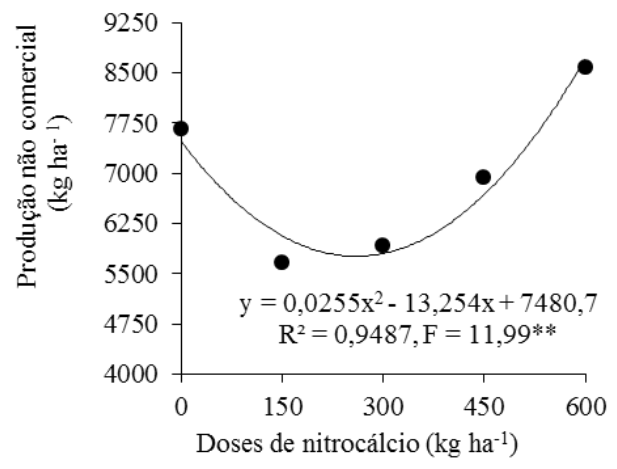

Figura 3. Valores médios da altura da parte aérea (A), matéria fresca da parte aérea (B), produção comercial (C) e produção não comercial (D) em função das doses de nitrocálcio na cultura da cenoura. Ipameri-GO, 2015. *, ** significativo a 5 e $1 \%$ de probabilidade, respectivamente.

\section{Conclusões}

As fontes de nitrogênio e épocas não influenciaram as características produtivas da cultura da cenoura em nenhuma das variáveis analisadas.

A utilização de doses de nitrogênio até $103 \mathrm{~kg} \mathrm{ha}^{-1}$ aumenta a produção comercial de cenoura.

As doses de potássio influenciaram as características do comprimento e diâmetro de raiz, classificação comercial, matéria seca da parte aérea e raiz além da produção comercial até a dose de $88 \mathrm{~kg} \mathrm{ha}^{-1}$.

As doses de nitrocálcio influenciaram positivamente a altura da parte aérea, matéria fresca da parte aérea, produção comercial e produção não comercial da cultura da cenoura até a dose de $311 \mathrm{~kg} \mathrm{ha}^{-1}$ do fertilizante.

\section{Agradecimentos}

A Universidade Estadual de Goiás (UEG), Campus Ipameri, pelo suporte na condução do projeto e pela bolsa produtividade PROBIP ao quarto autor. Ao CNPq pela bolsa de iniciação científica concedida ao terceiro e $\mathrm{PBIC/UEG}$ para o primeiro e segundo autor. 


\section{Referências Bibliográficas}

BRUNO, R. L. A.; VIANA, J. S.; SILVA, V. F.; BRUNO, G. B.; MOURA, M. F. Produção e qualidade de sementes e raízes de cenoura cultivada em solo com adubação orgânica e mineral. Horticultura Brasileira. Brasília-DF. v. 25, n. 2, p. 170-174, 2007.

CEAGESP. COMPANHIA DE ENTREPOSTOS E ARMAZÉNS GERAIS DE SÃO PAULO. Classificação de cenoura: programa de adesão voluntária, São Paulo-SP: CQH/CEAGESP, 2000. 5 p. (Folder). Disponível em: <http://www.hortibrasil.org.br/images/stories/folders/cenoura A4.pdf>. Acesso em: 24 jul. 2017.

COSTA, N. L.; SILVA, A. R. C.; GRANGEIRO, L. C. Efeito residual da adubação da cebola no rendimento de cenoura. Agropecuária Científica no Semi-Árido. Campina GrandePB, v. 8, n. 1, p. 07-11, 2012.

FERREIRA, M. M.; SILVA, C. A.; LOPES, S.; LOPES, F. A. Z.; REIS, L. L.; SOUSA, P. M. Produção de cenoura em função de doses de potássio e manejos de irrigação. Revista Agrogeoambiental. Pouso Alegre-MG, v.8, n.2, p.12-24, 2016.

FILGUEIRA, F. A. R. Novo manual de olericultura: agrotecnologia moderna na produção e comercialização de hortaliças. 3. ed. Viçosa-MG: UFV, 2012. 421p.

LUZ, J. M. Q.; ZORZAL FILHO, A.; RODRIGUES, W. L.; RODRIGUES, C. R.; QUEIROZ, A. A. Adubação de cobertura com nitrogênio, potássio e cálcio na produção comercial de cenoura. Horticultura Brasileira. Brasília-DF, v. 27 , n. 4 , p. 543-548, 2009.

MALAVOlTA, E.; VITTI, G. C.; OliVEIRA, S. A. Avaliação do estado nutricional das plantas: princípios e aplicações. 2. ed. Piracicaba-SP: Associação Brasileira para Pesquisa da Potassa e do Fosfato, 1997. 319 p.
NETO, F. B.; OLIVEIRA, L. J; SANTOS, A. P; LIMA, J. S. S.; SILVA, I. N. Otimização agroeconômica da cenoura fertilizada com diferentes doses de jitirana. Revista Ciência Agronômica. Fortaleza-CE, v. 45, n. 2, p. 305-311, 2014.

PRADO, R. M. Nutrição de plantas. São Paulo-SP: UNESP, 2008. $407 \mathrm{p}$.

RIBEIRO, A. C.; GUIMARÃES, P. T. G.; ALVAREZ, V. H. Recomendações para o uso de corretivos e fertilizantes em Minas Gerais - $\mathbf{5}^{\mathbf{a}}$ aproximação. Viçosa-MG: UFV, 1999. 359p.

TEIXEIRA, L. J. Q.; POLA, C. C.; JUNQUEIRA, M. S.; MENDES, F. Q.; RODRIGUES JUNIOR, S. R. Cenoura (Daucus carota): processamento e composição química. Enciclopédia Biosfera. Goiânia-GO, v. 7, n. 12, p. 1-21, 2011.

VAN RAIJ, B.; CANTARELLA, H.; QUAGGIO, J. A.; FURLANI, A. M. C. Recomendações de adubação e calagem para o estado de São Paulo. 2. ed. Campinas-SP: IAC, 1997. 285 p.

VIANA, E. M.; KIEHL, J. C. Doses de nitrogênio e potássio no crescimento do trigo. Bragantia, Campinas-SP, v. 69, n. 4, p. $975-982,2010$.

ZANFIROV, C. A.; CORREA, C. V.; CARPANETTI, M. G.; CORREA, F. F.; CARDOSO, A. I. I. Produção de cenoura em função das doses de potássio em cobertura. Horticultura Brasileira. Brasília-DF, v. 30, n. 4, p. 747-750, 2012.

ZONTA, E. P.; MACHADO, A. A.; SILVEIRA JÚNIOR, P. Sistema de análise estatística para microcomputadores: Manual de utilização. 2. ed. Pelotas-RS: UFPEL, 1987.

SANTOS, H. G.; JACOMINE, P. K. T.; ANJOS, L. H. C.; OLIVEIRA, V. A.; LUMBRERAS, J. F.; COELHO, M. R.; ALMEIDA, J. A.; CUNHA, T. J. F.; OLIVEIRA, J. B. Sistema brasileiro de classificação de solos. 3. ed. BrasíliaDF: Embrapa Solos, 2013. 353p 